\title{
Drenagem urbana: uma revisão de literatura
}

O crescente aumento da urbanização trouxe consigo problemas relacionados ao escoamento das águas, como por exemplo, a impermeabilização do solo. Na busca de solucionar estes problemas, a drenagem urbana é utilizada de maneira satisfatória para drenar as águas pluviais. Porém é importante que a gestão se atente para o desenvolvimento de um sistema de drenagem eficiente, que supra a necessidade de cada região. Assim, esta pesquisa teve como objetivo realizar uma revisão de literatura a respeito da importância da drenagem urbana. A metodologia utilizada foi a revisão de literatura do tipo descritiva e abordagem qualitativa. A amostra deste estudo foi composta por monografias, dissertações, teses e artigo de publicação nacional, idioma em português e data de publicação compreendida entre os últimos cinco anos. Para o levantamento da amostra, utilizou-se a base de dados Google Acadêmico, por meio do uso das palavras chaves: drenagem urbana. Ao final concluiu-se que a drenagem urbana é um sistema preventivo de inundações e tem como objetivo minimizar os riscos à população, diminuindo os prejuízos provocados pelas enchentes e inundações, viabilizando o desenvolvimento urbano de maneira harmônica, sustentável e articulada.

Palavras-chave: Águas Pluviais; Desenvolvimento Urbano; Drenagem Urbana.

\section{Urban drainage: a literature review}

The growing increase in urbanization has brought with it problems related to runoff, such as soil sealing. In order to solve these problems, urban drainage is used satisfactorily to drain rainwater. However, it is important that management pay attention to the development of an efficient drainage system, which meets the needs of each region. Thus, this research aimed to conduct a literature review regarding the importance of urban drainage. The methodology used was the literature review of the descriptive type and qualitative approach. The sample of this study was composed of monographs, dissertations, theses and articles of national publication, language in Portuguese and date of publication between the last five years. To survey the sample, the Google Scholar database was used, using the keywords: urban drainage. In the end, it was concluded that urban drainage is a flood prevention system and aims to minimize the risks to the population, reducing the damage caused by floods and floods, enabling urban development in a harmonious, sustainable and articulated manner.

Keywords: Rainwater; Urban Development; Urban Drainage.

Topic: Engenharia Civil

Reviewed anonymously in the process of blind peer.
Received: $11 / 04 / 2020$

Approved: $20 / 07 / 2020$

Luiz Antônio Cardoso Caldeira (D)

Faculdade em Porto Nacional, Brasil

http://lattes.cnpq.br/8658559691529118

http://orcid.org/0000-0003-0655-0137

luizantoniovoador@gmail.com

\section{Diogo Pedreira Lima}

Faculdade em Porto Nacional, Brasil

http://lattes.cnpq.br/7967728577417186

diogo.lima@itpacporto.edu.br

Referencing this:

CALDEIRA, L. A. C.; LIMA, D. P.. Drenagem urbana: uma revisão de literatura. Engineering Sciences, v.8, n.2, p.1-9, 2020. DOI: http://doi.org/10.6008/CBPC2318-3055.2020.002.0001 


\section{INTRODUÇÃO}

Os problemas resultantes da urbanização e do uso inadequado do solo pautam-se na redução da capacidade de armazenamento natural dos escoamentos, e devido a isto demandam outros locais para ocupar. Com a aceleração dos escoamentos acabe-se transferindo para jusante o problema de redução de espaços naturais, uma vez que quanto menor é o tempo de concentração, maior será o pico de vazão a jusante, o que acaba provocando inundações nas mais diversas áreas urbanas, pois a ocupação urbana normalmente se desenvolve no sentido de jusante para montante (CANHOLI, 2014).

O uso e ocupação do solo, provocada pela expansão urbana, induz a diversas consequências que são caracterizadas especialmente pela impermeabilização da bacia de drenagem, avanço desordenado da população e uso indevido da capacidade de suporte do meio, o que acaba degradando o meio ambiente (RIGHETTO et al., 2017). Assim, é importante a existência de uma rede de drenagem, uma vez que a mesma promove o bem-estar e a segurança da população (GIRÃO et al., 2017).

A rede de drenagem urbana é conceituada como sistema preventivo de inundações, especialmente nas áreas mais baixas das comunidades vulneráveis a alagamentos ou marginais aos cursos d'água (MEDAU, 2018). O Brasil é um país onde existem vários problemas urbanos provocados pelo sistema de drenagem ineficiente, especialmente quando se refere aos meses mais chuvosos. Estes problemas não são exclusivos das áreas periféricas da cidade, porém estes bairros, na maioria das vezes, são os que mais sofrem com tais problemas, justamente por serem menos saneados e não disporem de estruturas de micro e macrodrenagem urbana condizentes com as necessidades locais (FRAGOSO et al., 2016).

O desenvolvimento de um bom Plano Diretor de Desenvolvimento Urbano (PDDU), que é o instrumento básico da política de desenvolvimento e expansão urbana (BRASIL, 2007), pode "contribuir para a valorização, proteção e gestão equilibrada dos recursos naturais", além de viabilizar a eficiência dos serviços aliado à qualidade de vida e saúde de toda sociedade. Porém, alguns municípios têm demonstrado falta de harmonia entre os sistemas urbanos; que se apresentam ineficientes, defasados e separados uns dos outros. Este problema é maior nos municípios de pequeno porte e isto se justifica pela dificuldade na gestão e no planejamento territorial. São cidades que, de maneira geral, acabam se desenvolvendo de maneira desordenada até atingir o número de habitantes exigido legalmente, para só depois elaborarem seu plano. Por este motivo, os sistemas de drenagem são altamente impactados, sobressaindo como um problema provocado pela urbanização sem planejamento (TASCA et al., 2015). Desta maneira, a presente pesquisa tem como objetivo realizar uma revisão de literatura a respeito da importância da drenagem urbana.

\section{METODOLOGIA}

Trata-se de um estudo de revisão de literatura do tipo descritiva e abordagem qualitativa. Para Minayo (2012) a abordagem qualitativa se preocupa, com as ciências sociais, com um nível de realidade que não pode ser quantificado, apenas analisado e estudado. Já a pesquisa do tipo descritiva observa, registra e analisa fenômenos, sem manipulá-los. Procura descobrir a frequência, sua natureza, características e sua 
relação com outros fenômenos.

A amostra deste estudo foi composta por monografias, dissertações, teses e artigo de publicação nacional, idioma em português e data de publicação compreendida entre os últimos cinco anos. Para o levantamento da amostra, utilizou-se a base de dados Google Acadêmico, por meio do uso das palavras chaves: drenagem urbana. Outra variável selecionada no Google Acadêmico foi o período especifico para a busca, sendo que o mesmo foi selecionado entre 2015 a 2020. Durante a busca realizou-se o levantamento e seleção de 23 publicações, de maneira aleatória, para a execução do presente estudo.

\section{DISCUSSÃO TEÓRICA}

\section{Importância da drenagem urbana}

Os alagamentos, as inundações, os deslizamentos e as perdas dos rios e dos lagos são provocados pelos efeitos negativos das chuvas e são nestes problemas que é possível observar a importância de um bom serviço de drenagem e manejo de águas pluviais urbanas. Um bom serviço de drenagem viabiliza vários benefícios, dentre eles: valorização das propriedades existentes na área beneficiada; redução de gastos com manutenção de vias públicas; redução de danos às propriedades e do risco de perdas humanas; escoamento rápido das águas superficiais, facilitando o tráfego após as chuvas; condições razoáveis de circulação de veículos e pedestres em áreas urbanas, por ocasião de chuvas frequentes e/ou intensas; redução de impactos da chuva ao meio ambiente, como erosão e poluição de rios e lagos (MEDAU, 2018).

Segundo a Lei no 11.445/2007 que estabelece diretrizes nacionais para o saneamento básico, em seu Art. 20; inciso IV está preconizado "disponibilidade, em todas as áreas urbanas, de serviços de drenagem e manejo das águas pluviais, limpeza e fiscalização preventiva das respectivas redes, adequados à saúde pública e à segurança da vida e do patrimônio público e privado" (BRASIL, 2007). É importante destacar que a drenagem urbana é formada por um conjunto de sistemas como: sarjetas, bocas-de-lobo, condutos de ligação, poços de visitas, etc. (DINIZ et al., 2016). Para uma boa eficiência do sistema de drenagem, além de boa organização estrutural urbana composta por estes dispositivos, é importante atentar-se para a concepção do projeto e para sua execução, uma vez que assim, a obra de drenagem irá atender às necessidades do local com qualidade, menos onerosidade e maior segurança (PAULA et al., 2017).

Em uma pesquisa desenvolvida por Bezerra et al. (2016) na cidade de Assú/RN, sobre drenagem urbana de águas pluviais, os autores destacaram que a área pesquisada está inserida em área totalmente asfaltada, associada a um relevo com declividade considerada, onde o coeficiente de deflúvio tende a aumentar devido a impermeabilização do solo, o que acaba implicando em pouca infiltração da água no solo e, por consequência, em maiores escoamentos superficiais. Possui diversos pontos de alagamentos, onde a falta de um sistema adequado de drenagem, provoca o empoçamento da água precipitada, provocando problemas de transito, poluição, veiculação de doenças hídrica, além de prejuízos econômicos.

É importante destacar que a drenagem urbana possui como função primordial eliminar a água que, sob qualquer forma, atinge o solo urbano, captando-a e conduzindo-a para locais que menos afete a 
segurança e durabilidade de uma via. Um sistema de drenagem deve sempre ser bem planejado e bem projetado, pois caso contrário poderá levar a problemas como enchentes, inundações, degradação da malha viária dentre outros prejuízos à população e a infraestrutura urbana (AIRES et al., 2018).

Satiro et al. (2019) destacam que quando um município dispõe de um sistema completo de drenagem urbana de água pluviais, é possível proporcionar "menos impactos à população e ao meio ambiente, adequando uma melhor qualidade de vida para as pessoas e diminuindo gastos para o poder público com reconstruções de pavimentos, com doenças, com limpeza de ruas após as chuvas, entre outros".

\section{Microdrenagem}

Nas últimas décadas têm se observado um aumento populacional no Brasil, concentrando-se, especialmente, nos grandes centros urbanos, o que acaba formando as regiões metropolitanas, e provocando, na maioria das vezes, um crescimento desordenado e irregular, levando a uma série de problemas hidrológicos, e que tem provocado inúmeras inundações urbanas devido as alterações que ocorrem no escoamento natural das bacias hidrográficas. Assim, é importante e imprescindível que os centros urbanos possuam um planejamento que inclua o correto manejo das águas pluviais tendo a micro e a macrodrenagem como ferramentas do controle da drenagem urbana sustentável (NASCIMENTO et al., 2018).

A microdrenagem é um sistema que é projetado para atender a drenagem de precipitações que possuem risco moderado e é conceituada como "sistema de condutos pluviais ou canais em nível de loteamento ou de rede primária urbana". A microdrenagem aumenta a vazão e esgota todo o volume de águas para a jusante. É um tipo de drenagem necessária em áreas urbanas, uma vez que cria condições mínimas de circulação de veículos e pedestres na ocasião de ocorrência de chuvas (MEDAU, 2018).

Em um sistema de microdrenagem, os principais elementos são: sarjetas, meios-fios, bocas de lobo, poços de visita, condutos forçados, galerias, estação de bombeamento e os sarjetões (BEZERRA et al., 2016). É um sistema de drenagem que coleta e conduz a água escoada para a macrodrenagem e são, normalmente, avistados em sarjetas e meio fios que dirigem a água para as canalizações coletoras, que geralmente são subterrâneas. Essas canalizações coletoras transportam a água à estação de tratamento (MARQUES, 2019).

Em uma pesquisa desenvolvida por Fragoso et al. (2016) com o objetivo realizar um breve estudo das condições do sistema de drenagem urbana na cidade de Belém, Pará, os autores constataram que a falta de manutenção dos componentes que integram o sistema de microdrenagem, com as bocas de lobo e sarjetas deterioradas ocasionam alagamentos e transtornos para os pedestres. Nesta pesquisa os autores constataram que todas as bocas de lobo estavam obstruídas com resíduos sólidos, além de terem verificado que existiam desníveis nas calçadas de algumas avenidas, impedindo o escoamento da água para a sarjeta, ocasionando pontos de alagamento. Assim, os autores concluíram que é necessário planejar as medidas no sistema de drenagem juntamente com demais setores do saneamento, como o de gestão dos resíduos sólidos, abastecimento de água e sistema de esgotamento sanitário.

Em outra pesquisa realizada por Satiro et al. (2019) na cidade de Cajazeiras/PB, para verificar a 
situação do sistema de drenagem de águas pluviais da cidade. Na pesquisa os autores verificaram que existem diversos locais na cidade que o sistema de drenagem é afetado devido à presença de resíduos sólidos e de esgotos doméstico lançados em canais de escoamento, o que tem provocado entupimento de bocas de lobo, galerias e poluição difusa causando alagamentos e doenças. Ao final os autores ressaltaram que é importante que se implante um sistema completo de drenagem, o que irá proporcionar menos impactos ao meio ambiente e à população, além de reduzir os gastos do poder público com reconstruções de pavimentos.

Daltoé et al. (2016) analisaram a rede de microdrenagem do município de Pelotas/RS e constataram uma frequência de $100 \%$ de plásticos, madeira e material orgânico em onze pontos distintos da rede. Que tem provocado alagamentos, em dias de chuvas, tornando a trafegabilidade prejudicada nas vias públicas. Desta maneira os autores ressaltaram a importância da implantação de um sistema de controle de pontos de alagamentos como maneira de diminuir os impactos provocados pela falta de drenagem e manejo das águas pluviais. Os autores deram como exemplo a realização da limpeza dos microdrenos.

Assim, é importante destacar que a drenagem das águas pluviais é um fator primordial para o meio urbano, uma que, quando se utiliza de sistemas de drenagem devidamente dimensionados e executados, consegue-se diminuir riscos de perdas materiais provenientes de inundações, auxilia a gestão pública no saneamento ambiental e também contribui para a saúde pública e para a qualidade de vida das pessoas (PINTO et al., 2017).

\section{Macrodrenagem}

A macrodrenagem é conceituada como um sistema que coleta águas de chuvas nas áreas urbanas por meio de galerias pluviais que formam grandes troncos coletores. $\mathrm{O}$ sistema de macrodrenagem se constitui:

Por sistemas naturais ou construídos, que recebem as águas de uma bacia de drenagem e as leva para uma outra estrutura de macrodrenagem a jusante - rios, córregos, lagoas, represas - ou para o oceano. Desta forma, a microdrenagem realiza uma captação primaria das águas de chuva e as conduz para os sistemas de macrodrenagem. (TRAVASSOS, 2004, citado por NASCIMENTO et al., 2018)

A macrodrenagem é constituída por estruturas, como galerias e estruturas de dispersão de energia, como: rampas dentadas, vertedores, blocos de impacto e degraus. Este tipo de drenagem tem como objetivo controlar a erosão urbana direcionando adequadamente as águas pluviais até o curso d'água receptor. É importante destacar que a macrodrenagem deve sempre considerar as transformações no uso e ocupação do solo (OTTONI et al., 2018).

Ao se projetar um sistema de macrodrenagem urbana, deve-se pensar em adotar canais abertos, uma vez que estes são vistos como solução por apresentar vantagens como: facilidade de limpeza e manutenção, versatilidade como a adoção de seções mistas, economia nos investimentos e maior facilidade para ampliações, caso sejam necessárias. Outro ponto a ser considerado diz respeito ao dimensionamento deste tipo de sistema, uma vez que o mesmo deve ser construído para atender a um período de retorno entre 25 a 100 anos, uma vez que os dispositivos devem ser dimensionados para suportar grandes picos de vazão (FARIAS, 2017). 
Andrade et al. (2017) realizaram uma pesquisa com o objetivo de diagnosticar o sistema de drenagem urbana e saneamento básico da área no entorno do Igarapé do Tucunduba pertencente a bacia do Tucunduba na cidade de Belém/PA. Nesta pesquisa os autores constataram que existe um grande despejo de resíduos sólidos e esgoto doméstico no canal, o que aumentado a impermeabilização do solo e o escoamento superficial da água, o que está provocando inundações urbanas e assoreamento do canal. A bacia do Igarapé do Tucunduba possui um projeto de macrodrenagem que foi desenvolvido para garantir qualidade de vida aos moradores da área, porém devido à urbanização acelerada o canal está sendo assoreado, diminuindo a profundidade do mesmo e aumentando os riscos de inundações. Os autores destacaram, ainda, que o assoreamento é resultado, também, da retirada da mata ciliar e do processo erosivo da área.

Na pesquisa desenvolvida por Fragoso et al. (2016) realizada em Belém/Pará, os autores constataram que em muitos canais de macrodrenagem dos bairros pesquisados existia um processo de eutrofização ${ }^{1}$ das águas, provocado pelo excesso de lançamentos irregulares de esgotos sanitários domésticos. Por este motivo, em épocas de chuva, o trânsito de pedestres no local se torna quase impossível devido as inundações provocadas pelo transbordo do canal, além de provocar consequências como a transmissão de doenças causadas pelo contato com a água poluída. Os autores ressaltaram, ainda, que a causa dos alagamentos também está associada à ocupação irregular ao longo do canal, que acabou diminuindo a área de infiltração.

\title{
Problemas ocasionados pela falta de drenagem adequada
}

A necessidade de investimentos em infraestrutura surge a partir da urbanização, ou seja, com o aumento significativo da população é necessário que a cidade se desenvolva de maneira mais igualitária, proporcionando moradias com qualidade, saneamento e drenagem de águas pluviais para prevenir inundações e enchentes que se configuram como problemas devido as cidades possuírem extensas áreas impermeáveis (asfalto, concreto), o que acaba dificultando a infiltração da água no solo. Essa impermeabilização é provocada pela urbanização e caso não haja um bom planejamento urbano, é impossível prevenir o surgimento de vários problemas para a população (BEZERRA et al., 2016).

Quando se desenvolve um sistema de drenagem sem planejamento urbano, o mesmo pode apresentar falhas que afeta toda a sociedade de um determinado local ou cidade. Sobre isto, Monte (2008) apud Nascimento et al. (2018) afirma que:

\begin{abstract}
Todo este processo, quando não implantado e gerenciado de forma planejada e sustentável, acaba gerando vários problemas, tais como: enchentes, inundações, enxurradas e consequente contaminação dos rios, resultando em diversos impactos socioambientais como, por exemplo, a alteração da qualidade das águas dos córregos provenientes da carga de poluentes, assim como de resíduos sólidos lançados juntamente com as águas pluviais; surgimento de erosões; escorregamento de encostas; além de problemas relacionados a saúde pública (com veiculação de doenças) e interdição de vias com prejuízo ao trânsito de veículos. (MONTE, 2008, citado por NASCIMENTO et al., 2018)
\end{abstract}

Um exemplo claro destes problemas fora constatado por Moura et al. (2018) na cidade Ceres, Goiás por meio de uma pesquisa realizada com o objetivo de apresentar os problemas de uma das redes de

\footnotetext{
${ }^{1}$ Processo normalmente de origem antrópica (provocado pelo homem), ou raramente de ordem natural, tendo como princípio básico a gradativa concentração de matéria orgânica acumulada nos ambientes aquáticos.
} 
drenagem localizada em uma nascente dentro da cidade. Os autores relataram que a urbanização acelerada da cidade levou à canalização de cursos d'água, o que tem provocado alagamentos devido à falta de drenagem apropriada e o aumento da velocidade da água durante as chuvas, o que tem provocado impactos à jusante. Quanto a drenagem, os autores verificaram que existem várias construções no entorno da rede de drenagem, especificamente nas caixas de retenção, oferecendo riscos à estrutura, à população e também ao curso d'água. As caixas de retenção além de estarem expostas devido às construções em seu entorno, ainda foram construídas com materiais impróprios (tijolo maciço de barro), o que indica a necessidade de um projeto que possa atender a demanda atual da água para assim eliminar os problemas como é o caso das inundações.

Em outra pesquisa realizada por Valim et al. (2015) no Parque Alfredo Werner Nyffeler em Maringá/PR, os autores constataram que o sistema de drenagem implantado no local se encontra depreciada, com vazamentos e remendos com argamassa a fim de conter o problema temporariamente. É uma tubulação que, com o passar do tempo, tornou-se insuficiente para os picos de vazão. Os autores verificaram, ainda, que a camada mais superficial do solo do local é formada por um aterro para nivelar o terreno para a passagem da tubulação até a montante do riacho, que é o ponto de descarga da drenagem. Todo esse processo acelerou o processo de erosão que tomou conta de parte da tubulação, podendo levar toda a estrutura ao colapso.

O problema de erosão devido a ineficiência do sistema de drenagem também foi constatado na pesquisa desenvolvida por Barros et al. (2019) na cidade de Gurupi/TO. Nesta pesquisa os autores verificaram que o município possui um sistema de drenagem que está em mau funcionamento, o que tem provocado erosões, alagamentos, enchentes, o que acaba dificultando o trafego de veículos e pedestres. Os pontos críticos da drenagem urbana pautam-se pela falta de bocas de lobo, baixa permeabilidade, elevada declividade que contribui para o alagamento de certos pontos da cidade. Os autores destacaram, ainda, sobre a importância de alinhar o sistema de "macrodrenagem ao de microdrenagem, ou seja, na formulação do sistema de drenagem de uma cidade é necessário que antes da macrodrenagem, possua a microdrenagem, para que juntos possam escoar a água adequadamente".

Assim, é importante destacar que os sistemas de drenagem são importantes e previnem a poluição difusa urbana, ou seja, os alagamentos, as inundações, as erosões e os assoreamentos, especialmente em áreas a jusante dos cursos naturais d'água. Com a urbanização desordenada e a falta de políticas e investimentos públicos voltados para a drenagem urbana os problemas acabam agravando-se, trazendo transtornos tanto para a população quanto para os gestores públicos (MARTINS, 2019).

\section{CONCLUSÕES}

Neste trabalho foi possível concluir que a drenagem urbana é um sistema preventivo de inundações e tem como objetivo minimizar os riscos à população, diminuindo os prejuízos provocados pelas enchentes e inundações, viabilizando o desenvolvimento urbano de maneira harmônica, sustentável e articulada. Podese dizer que a drenagem urbana é o gerenciamento da água da chuva que escoa no meio urbano. Assim, 
concluiu-se que a importância da drenagem urbana está pautada na prevenção dos efeitos negativos provocados pelas chuvas, efeitos estes que se pautam em: deslizamentos, erosões, alagamentos, inundações, além de prevenir a perda dos rios e lagos.

Percebeu-se que a urbanização desordenada agrava os problemas da drenagem urbana devido a ocorrência da impermeabilização do solo por meio de obras de infraestrutura como ruas, calçadas, pátios, dentre outros, o que dificulta a infiltração da água no solo. Devido a estas obras de infraestrutura a água passa a transcorrer por condutos, aumentando o escoamento superficial, ou seja, o volume de água que transcorria pelo solo e era retido pelas plantas, passa a ser transportado pelos canais de drenagem, exigindo, cada vez mais, maior capacidade de escoamento.

\section{REFERÊNCIAS}

AIRES, T. R. B.; OLIVEIRA, J. M.; CORDEIRO, D. H. G.; PACHECO, L. L. L.; SILVA, M. H. A.; FREITAS, S. X.. Degradação do asfalto causado por drenagem urbana ineficiente. Ceres: Associação Educativa Evangélica, 2018.

ANDRADE, A. A.; NORAT, M. V. C.. Diagnóstico do sistema de macrodrenagem do Igarapé do Tucunduba pertencente à bacia do Tucunduba, Belém/PA. FENASAN, 2017.

BARROS, H.; RODRIGUES, C. R.; MENDES, A. S.. Estudo hidrológico para fins de drenagem urbana em Gurupi/TO. Revista Científica Semana Acadêmica, Fortaleza, n.183, 2019.

BEZERRA, A. M.; QUEIROZ NETO, M. L.; FLORÊNCIO, F. D. C.; OLIVEIRA, A. S.; SOUZA JUNIOR, P. L.. Drenagem urbana de água pluviais: cenário atual do sistema da cidade de Assú/RN. In: CONGRESSO BRASILEIRO DE GESTÃO AMBIENTAL CAMPINA GRANDE/PB, 7. Anais. 2016.

BRASIL. Presidência da República. Lei n. 11.445, de 05 de janeiro de 2007. Casa Civil. Brasília: DOU, 2007.

CANHOLI, A. P.. Drenagem urbana e controle de enchentes. 2 ed. São Paulo: Oficina de Textos, 2014.

DALTOÉ, M. F.; CASTRO, A. S.; CORRÊA, L. B.; LEANDRO, D.; BARCELOS, A. A.. Resíduos Sólidos na rede de microdrenagem: uma análise qualitativa na cidade de Pelotas/RS. Revista Monografias Ambientais, v.15, n.1, p.175-188, 2016. DOI: http://doi.org/10.5902/22361308

DINIZ, C. M.; RANGEL, M. P.; OLIVEIRA, M. B.; ROSTANGO, P. V.. A interferência das redes subterrâneas na qualidade da pavimentação urbana: comparativo econômico entre alternativas de traçado. Revista Interdisciplinar do Pensamento Científico, n.2, v.2, 2016. DOI: http://dx.doi.org/10.20951/2446-6778/v2n2a1

FARIAS, K. S.. Análise quantitativa de macrodrenagem urbana: avaliação da capacidade de escoamento de um canal no município de Delmiro Gouveia/AL. Monografia (Bacharelado em Engenharia Civil) - Universidade Federal de Alagoas, Delmiro Gouveia, 2017.

FRAGOSO, G. A.; SILVA, F. P.; SILVA, J. C. C.; ALVES, A. F.; CARVALHO, B. G. P.. Planejamento, ordenamento e gestão integrada. Diagnóstico do sistema de drenagem urbana da cidade de Belém, Pará: uma análise dos principais bairros da cidade. In: ENEEAMB, 4; FÓRUM LATINO, 2; SBEA - CENTROOESTE, 1. Anais. Brasília, 2016.

DOI: http://doi.org/10.5151/engpro-eneeamb2016-pogi003-5067

GIRÃO, L. F. O.; SIMÕES, N. E. C.; MARQUES, J. A. A.; LEITÃO, J. P. C.; PINA, R. D.. Modelação hidráulica e de qualidade da água dos sistemas de drenagem em meios urbanos. Eng. Sanit. Ambient., v.22, n.2, p.351-360, 2017. DOI: http://doi.org/10.1590/S1413-41522016161318

MARQUES, V. P.. Estudo de medidas estruturais em planos diretores de drenagem urbana. Monografia (Bacharelado em Engenharia Civil) - Universidade Federal de Ouro Preto, Ouro Preto, 2019.

MARTINS, S. Q.. Verificação do sistema de drenagem urbana e das áreas com risco de erosão no bairro Itamaraty 2ª etapa em Anápolis, GO. Monografia (Bacharelado em Engenharia Civil) - Centro Universitário de Anápolis, Anápolis, 2019.

MEDAU, I.. Análise dos dispositivos de drenagem urbana na Avenida São Francisco, Anápolis/GO. Monografia (Bacharelado em Engenharia Civil) - Centro Universitário de Anápolis, Anápolis, 2018.

MINAYO, M. C. S.. Análise qualitativa: teoria, passos e fidedignidade. Ciênc. Saúde Coletiva, v.17, n.3, p.621-626, 2012. DOI: http://doi.org/10.1590/S141381232012000300007

MOURA, E. M.; NASCIMENTO, N. C.; BATISTA, M. S.; MARTINS, A. F. A.. Sistema de drenagem em nascente: estudo de caso na cidade de Ceres, Goiás. In: Simpósio Nacional de Ciência e Meio Ambiente, 8. Anais. SNCMA, 2017

NASCIMENTO, V. H. A.; STOLL, W. J.; MARTILIANO, A. J.; SANTOS, G. P.; REZENDE, S. P.. Problemas da impermeabilização excessiva do solo. In: COLÓQUIO ESTADUAL DE PESQUISA MULTIDISCIPLINAR, 2; CONGRESSO NACIONAL DE PESQUISA MULTIDISCIPLINAR, 1. Anais. 2018.

OTTONI, A. B.; ROSIN, J. A. R. G.; FOLONI, F. M.. Drenagem 
urbana: soluções alternativas sustentáveis. Tupã: Associação Amigos da Natureza, 2018.

PAULA, J. S.; SILVA, J. S.; OLIVEIRA, M. A. F.; RANGEL, M. P.. Execução de obras de drenagem pluvial: princípios empregados na construção de redes de drenagem urbana. Revista Interdisciplinar do Pensamento Científico, n.2, v.3, 2017. DOI: http://dx.doi.org/10.20951/2446-6778/v3n2a15

PINTO, J. A.; RIBEIRO JUNIOR, L. U.. Contribuição para o dimensionamento de sistemas de microdrenagem urbana. Revista Científica Universitas, Itajubá, v.4, n.2, p.16-30, 2017.

RIGHETTO, A. M.; GOMES, K. M.; FREITAS, F. R. S.. Poluição difusa nas águas pluviais de uma bacia de drenagem urbana. Eng. Sanit. Ambient., v.22, n.6, p.1109-1120, 2017. DOI: http://10.1590/S1413-41522017162357
SATIRO, R. S.; LIMA, R. G.; SOUSA, F. C. F.; DUARTE, F. K. D.; SOUSA, F. C. F.. Drenagem urbana de água pluviais: cenário atual do sistema da cidade de Cajazeiras/PB. In: CONGRESSO INTERNACIONAL DE MEIO AMBIENTE E SOCIEDAD, 1; CONGRESSO INTERNACIONAL DA DIVERSIDADE DO SEMIÁRIDO, 2. Anais. 2019.

TASCA, F. A.; POMPÊO, C. A.; FINOTTI, A.. Gestão da drenagem urbana em municípios de pequeno porte da bacia hidrográfica do Rio Itajaíaçu. In: SIMPÓSIO BRASILEIRO DE RECURSOS HÍDRICOS, 21. Anais. Brasília, 2015.

VALIM, F. A.; ORIOLI, C. M. P.; ILDEFONSO, J. S.; GUTIERREZ, N. H. M.. Diagnóstico visual do sistema de drenagem e erosão a jusante do Parque Alfredo Werner Nyffeler em Maringá/PR. Revista Eletrônica em Gestão, Educação e Tecnologia Ambiental Ed. Especial GIAU-UEM, Maringá, v.19, p.30-38, 2015.

A CBPC - Companhia Brasileira de Produção Científica (CNPJ: 11.221.422/0001-03) detém os direitos materiais desta publicação. Os direitos referem-se à publicação do trabalho em qualquer parte do mundo, incluindo os direitos às renovações, expansões e disseminações da contribuição, bem como outros direitos subsidiários. Todos os trabalhos publicados eletronicamente poderão posteriormente ser publicados em coletâneas impressas sob coordenação da Sustenere Publishing, da Companhia Brasileira de Produção Científica e seus parceiros autorizados. Os (as) autores (as) preservam os direitos autorais, mas não têm permissão para a publicação da contribuição em outro meio, impresso ou digital, em português ou em tradução. 